\title{
Analysis of intestinal intraepithelial lymphocyte populations in experimental Trichinella spiralis infection of mice
}

\author{
Frane Božić ${ }^{1}$, Albert Marinculić ${ }^{2}$ and Emir Duraković ${ }^{2}$ \\ ${ }^{1}$ Department of Pharmacology and Toxicology, Veterinary Faculty, University of Zagreb, Heinzelova 55, 10000 Zagreb, Croatia; \\ ${ }^{2}$ Department of Parasitology, Veterinary Faculty, University of Zagreb, Heinzelova 55, 10000 Zagreb, Croatia
}

Key words: Trichinella spiralis, goblet cells, i-IELs, gut

\begin{abstract}
The potential role of intestinal intraepithelial lymphocytes (i-IELs) in the generation of host protective immunity after helminth infection was investigated using the Trichinella spiralis (Owen, 1835)/mouse model. In this study we found a significant rise of TCR $\gamma \delta^{+}$i-IELs $(\mathrm{P}<0.001)$ concurrent with the jejunal goblet cells $(\mathrm{GC})$ hyperplasia in $T$. spiralis-infected C57BL mice on day 4 p.i. However, no direct relationship between the kinetics of the increase in TCR $\gamma \delta^{+}$i-IELs and T. spiralis expulsion was observed in infected mice. Taken together, these results implicate that $\gamma \delta \mathrm{i}$-IELs probably perform a unique functions related to the regulation of the GC proliferation accompanying T. spiralis gut infection. As is known, these TCR $\gamma \delta^{+}$ i-IELs may release mediators or growth factors that in turn influence GC differentiation. With the use of dexamethason (DEX), a potent anti-inflammatory agent which also induces apoptotic cell death in i-IELs, we have confirmed that the expulsion of T. spiralis from the mouse gut is accompanied by an inflammatory response. Indeed, the GC are clearly involved in these phenomena, apparently under the regulation by TCR $\gamma \delta^{+}$i-IEL-mediated responses, since DEX abrogated GC proliferation in T. spiralis-infected C57BL mice and subsequently augmented adult worm burden. Our data also show that the rejection of adult worms starts concurrently with a significant increase in TCR $\alpha \beta^{+}$and $C D 8^{+}$i-IELs $(\mathrm{P}<0.05$ and $\mathrm{P} \leq 0.01$, respectively), namely by day 7 p.i. At the same time, $\mathrm{CD}^{+}$cells significantly decreased $(\mathrm{P}<0.05)$ in the intestinal epithelium of $T$. spiralis-infected, $v s$ uninfected mice. These results may indicate that the TCR $\alpha \beta^{+}$and $\mathrm{CD} 8^{+} \mathrm{i}$-IELs act as effectors of anti-T. spiralis defence reactions. The implications of these findings for the potential role of intestinal intraepithelial $\mathrm{CD} 8^{+}$and $\mathrm{TCR} \alpha \beta^{+}$cells in the pathogenesis of the intestinal lesions during $T$. spiralis gut infection are discussed.
\end{abstract}

Most studies of Trichinella spiralis (Owen, 1835) infections in the gut have focused on $\mathrm{T}$ cell responses in the spleen, the peripheral lymph nodes or the gut lamina propria but there are few reports about the role of intestinal intraepithelial lymphocytes (i-IELs) (Dillon et al. 1986, Garside et al. 1992, Božić et al. 1998). Most of the i-IELs are $\mathrm{CD}^{+} \mathrm{CD} 8^{+}$cells, consisting of a heterogeneous populations (Lefrancois 1991). Unlike the majority of peripheral $\mathrm{T}$ cells, a significant fraction of i-IELs is derived from bone marrow without thymic maturation (Rocha et al. 1991, Poussier et al. 1992) and these i-IELs may be involved in front-line defence during the response to infectious agents. Apart from their intrinsic cytotoxic capacity and possible participation in immunity, the function of i-IELs is often associated with a regulatory rather than with an effector role. Several lines of evidence support the important role of i-IELs in the maintenance of epithelial homeostasis (Boismenu and Havran 1994, Boismenu et al. 1996), as well as in goblet cell (GC) proliferation (Housley et al. 1994).

Indeed, the GC hyperplasia, regulated by $\mathrm{T}$ lymphocytes (Garside et al. 1992), may be an important factor in the expulsion of $T$. spiralis adult worms from the gut. Parasite expulsion is associated with intestinal pathology in the T. spiralis model system and both of these phenomena are $\mathrm{T}$ cell dependent (Manson-Smith et al. 1979, Garside et al. 1992). Although the role of T lymphocyte subsets has not been established, it seems that the immune expulsion of $T$. spiralis adults is associated with inflammatory responses mediated by $\mathrm{CD}^{+} \mathrm{T}$ cells (Wakelin 1993). However the effector mechanisms directly responsible for nematode loss have not been elucidated. Furthermore, there are few reports about the role of $\mathrm{CD}^{+}$cells in this phenomenon (Karmanska et al. 1995).

Since the initial cellular events that take place at the outset of $T$. spiralis infection are poorly understood, especially the participation of, and role for, i-IELs it is necessary to examine this issue. Therefore, in this study, a range of parasitological, histological and immunological parameters were examined in C57BL mice at different intervals after primary infection by the gut nematode $T$. spiralis.

\section{MATERIALS AND METHODS}

The Trichinella used in this study was $T$. spiralis (MSUS/PO/60/ISS3), obtained from the Trichinella Reference Centre (Istituto Superiore di Sanità, Rome, Italy). The methods used for infecting mice and recovering $T$. spiralis worms were as described previously (Wakelin and Wilson 1977). 
Male C57BL mice, aged 10-14 weeks, obtained from "Ruđer Bošković" Institute, Zagreb, Croatia, were infected with $200 \mathrm{~T}$. spiralis infective muscle larvae (L1) on day 0 . Infected mice were sacrificed on 1, 4, 7, 14 and 21 days following infection. The small intestines were excised for immunophenotyping, histological studies and parasitological evaluation. In each of five separate experiments, experimental (infected) and uninfected (control) groups consisted of 3-5 animals.

Another group of mice $(\mathrm{n}=14)$ was injected subcutaneously (s.c.) with dexamethasone (DEX) (DEX pivalat, Plivacor $^{\circledR}$ ) (Pliva, Zagreb, Croatia) at $2 \mathrm{mg} \mathrm{ml}^{-1}$ one day prior to infection (day -1) with $200 \mathrm{~T}$. spiralis L1 larvae (day 0 ). Intestinal samples were removed for enumeration of adult worms $(\mathrm{n}=7)$ and GC counts $(\mathrm{n}=7)$ at day 4 following infection.

The i-IELs were isolated from mouse small intestine as previously described (Božić et al. 1998). The surface phenotype of isolated purified i-IELs was analysed about $2 \mathrm{~h}$ after cell preparation.

All the monoclonal antibodies (MAb) used in this study were obtained from Dianova/Pharmingen (Hamburg, Germany): PE-conjugated anti-CD8 $\alpha$ (Ly-2), PE-conjugated anti-CD4 (L3T4), PE-conjugated anti-CD3 $\varepsilon$, FITC-conjugated anti-TCR $\alpha \beta$ (H57) and FITC-conjugated anti-TCR $\gamma \delta$ (GL3). Data acquisition and one colour flow cytometry analysis were performed on a FACScan using the Cellquest program (Becton Dickinson, San Diego, USA). Single cell suspensions were prepared and incubated with Mabs $\left(10 \mu \mathrm{g} / 10^{6}\right.$ cells $)$ as previously described (Božić et al. 1998). Data are presented as the mean \pm standard deviation (SD) percent of the total number of cells in the lymphocyte gate expressing a specific antigen. The lymphocyte gate was set according light scatter properties of mouse lymphocytes.

For histological evaluation, a $2-\mathrm{cm}$ portion of the proximal jejunum was excised from individual mice, opened longitudinally, and after removing any of the intestinal contents the samples were fixed in $10 \%$ buffered formalin. After fixation, tissue samples were trimmed and embedded in paraffin wax according to routine techniques. Paraffin wax sections were cut at 4-5 $\mu \mathrm{m}$ and stained, either with haematoxylin and eosin $(\mathrm{H} \& \mathrm{E})$ or periodic-acid-Schiff (PAS). The number of PAS-positive GC in the jejunum was counted per area unit using a compound microscope with a net reticle. The GC were enumerated per $\mathrm{mm}^{2}$ of the villus/crypt unit along 10 randomly selected areas from each sample and averaged. The averaged number of GC in infected mice was then compared with the mean number of GC in uninfected animals.

Levels of significance between uninfected and infected groups of animals were determined by the two-tailed Student's $t$-test. A value of $\mathrm{P}<0.05$ was considered significant.

\section{RESULTS}

\section{Trichinella spiralis adult worm expulsion}

Mice infected with $200 \mathrm{~L} 1 \mathrm{~T}$. spiralis larvae were killed in groups of 3-5 on days 1, 4, 7, 14 and 21 after infection, and the numbers of adult worms counted. The results (Fig. 1) show that the $T$. spiralis worm burden at

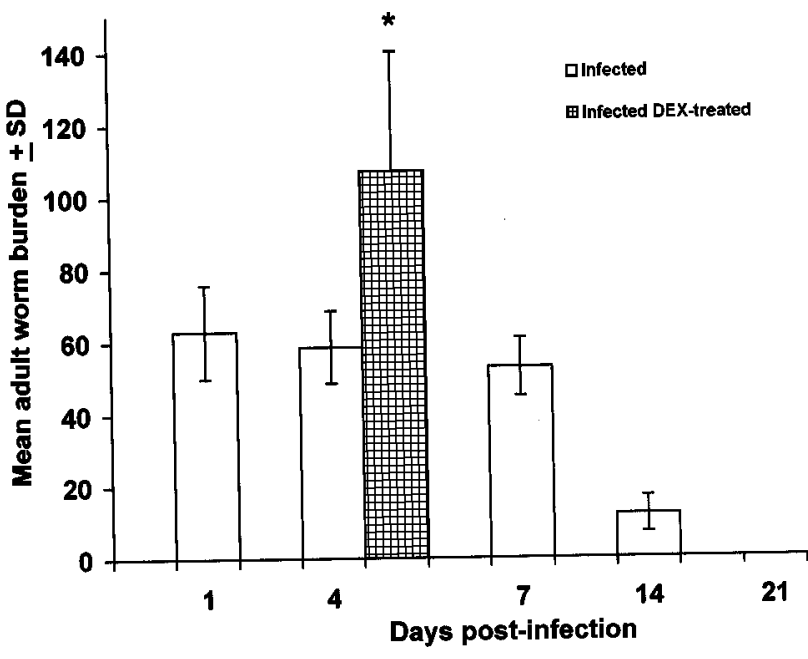

Fig. 1. Time-course of infection in C57BL mice infected with 200 L1 larvae of Trichinella spiralis. Mice were killed in groups of 3-5 at each time-point after infection. Dexamethasone-treated (day -1) and T. spiralis-infected (day 0) mice $(n=7)$ killed on day 4 after infection with $200 \mathrm{~L} 1$. Significant difference $(* \mathrm{P}<0.05)$ in adult worm burden between infected and infected dexamethasone-treated groups of mice.

day 7 p.i. was high and that expulsion of the parasite began after day 7 and was virtually complete by day 14 . No adult worms were recovered at day 21 in T. spiralisinfected C57BL mice.

In the gut of DEX-treated (day -1) and T. spiralisinfected (day 0$)$ mice $(n=7)$, killed on day 4 following infection with $200 \mathrm{~L} 1$, the adult worms reached significantly higher level $(\mathrm{P}<0.05)$ when compared with the infected untreated group of mice (Fig. 1).

\section{Jejunal goblet cell kinetics}

By day 4, the number of PAS-positive GC significantly increased in the jejunum of $T$. spiralisinfected mice in comparison with uninfected controls (Fig. 2). No differences in PAS-positive GC density between uninfected and infected DEX-treated groups were found on day 4 p.i. (Fig. 2).

\section{Dichotomy in i-IELs activation during Trichinella spiralis gut infection}

In C57BL mice, T. spiralis infection with $200 \mathrm{~L} 1$ larvae was followed by dramatic changes in the i-IELs. Increases in TCR $\gamma \delta^{+}$i-IELs occurred from 4 p.i. days, but although these cells increased significantly on day 4 $(40.1 \pm 1.6$ vs $28.8 \pm 1.8$ on day $0 ; \mathrm{P}<0.001)$, at day 7 p.i. only slight, but not statistically significant, increases in TCR $\gamma \delta^{+}$i-IELs occurred $(32.2 \pm 1.7$ vs $28.8 \pm 1.8$ on day $0 ; \mathrm{P}>0.05)$. At the same time, the proportion of TCR $\alpha \beta^{+}$i-IELs also increased on days 4 and 7 in the intestines of mice infected with $T$. spiralis. However, TCR $\alpha \beta^{+}$cells increased significantly $(\mathrm{P}<0.05)$ on day 7 , but not on day $4(\mathrm{P}>0.05)$ following Trichinella- 


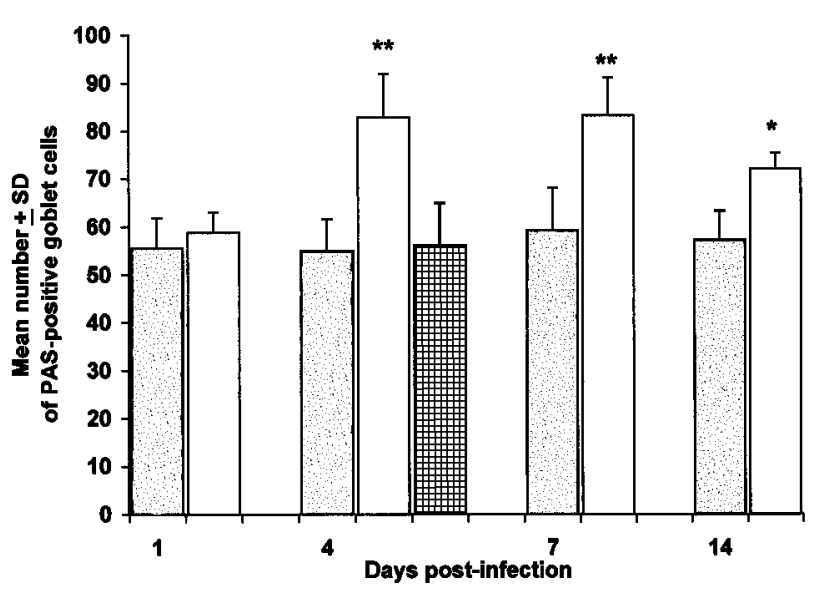

Fig. 2. PAS-positive profile of goblet cells in the jejunum of groups of 3-5 uninfected and Trichinella spiralis-infected mice expressed as mean number \pm SD of goblet cells per $\mathrm{mm}^{2}$ of the villus/crypt unit. Significant difference $(* \mathrm{P}<0.05$ and $* * \mathrm{P}<0.01)$ in PAS-positive goblet cell count between two groups (infected and uninfected) of mice. No differences in goblet cell numbers between uninfected $(\mathrm{n}=3-5)$ and Trichinella spiralis-infected dexamethasone-treated groups of mice $(\mathrm{n}=7)$ exist.

- uninfected; the left-most bars in each group

- Trichinella spiralis-infected; right of "uninfected"

- Trichinella spiralis-infected dexamethasone-treated

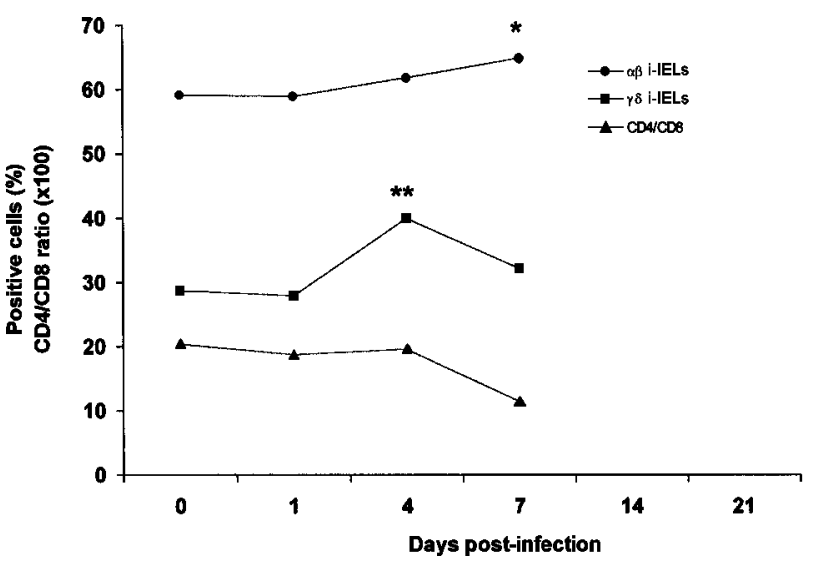

Fig. 3. Time-course of intestinal intraepithelial TCR $\alpha \beta$ cells $(\%), \mathrm{TCR} \gamma \delta$ cells $(\%)$, and $\mathrm{CD} 4 / \mathrm{CD} 8$ ratio in $\mathrm{C} 57 \mathrm{BL}$ mice infected with 200 L1 Trichinella spiralis larvae. Mean percentage from groups of two to four mice in each of 5 separate experiments is plotted. Significant difference from the value of uninfected mice $\left(* * \mathrm{P}<0.001\right.$ and ${ }^{*} \mathrm{P}<0.05$ for $\mathrm{TCR} \gamma \delta$ and TCR $\alpha \beta$ i-IELs, respectively. infection $(64.0 \pm 1.6$ and $61.8 \pm 8.2$, respectively, $v s$ $59.1 \pm 2.1$ on day 0$)$.

Early after infection (on day 1 ) $\mathrm{CD} 4^{+} \mathrm{T}$ cells slightly decreased $v s$ controls and continued to drop until day 7 when these cells decreased significantly $(8.0 \pm 0.9 \mathrm{vs}$ $13.3 \pm 2.9$ on day $0 ; \mathrm{P}<0.05)$. On the other hand, $\mathrm{CD} 8^{+}$ cells continued to rise and increased significantly on day 7 p.i. $(69.4 \pm 1.1$ vs $65.0 \pm 1.7$ on day $0 ; \mathrm{P} \leq 0.01)$.

Although uninfected mice normally had values less than one, the CD4/CD8 ratio continued to drop in the gut epithelium of the T. spiralis-infected mice. An inverse correlation between the intestinal intraepithelial $\mathrm{TCR} \alpha \beta^{+}$, but not $\mathrm{TCR} \gamma \delta^{+}$, cell level and the CD4/CD8 ratio was observed in $T$. spiralis-infected mice (Fig. 3).

Between 7 and 14 days after T. spiralis gut infection i-IELs population declined to almost undetectable values, coincided with maximal villus pathology, thus isolation failed.

\section{DISCUSSION}

The results of this study show that i-IELs may be involved in the generation of host protective immunity following $T$. spiralis gut infection of C57BL mice. However the response of $\gamma \delta$ i-IELs to $T$. spiralis infection occurs faster than that of $\alpha \beta$ i-IELs which implicate their different functions. A significant rise of $\gamma \delta$ i-IELs concurrent with the jejunal GC hyperplasia observed in T. spiralis-infected mice on day 4 p.i. (Figs. 2 , 3) suggest that $\gamma \delta$ i-IELs may act as initiators (regulators) of anti-Trichinella defence reactions, possibly performing specialised functions related to the regulation of the jejunal GC proliferation accompanying T. spiralis gut infection. However, such unique activities of $\gamma \delta$ i-IELs in T. spiralis-infected mice have not yet been demonstrated directly. Nevertheless, it is well known that $\gamma \delta$ i-IELs play an important role in the maintenance of epithelial homeostasis (Boismenu et al. 1996) enhancing the growth and functions of epithelial cells via production of keratinocyte growth factor (Boismenu and Havran 1994) which specifically increases GC differentiation (Housley et al. 1994). Therefore (although not yet been proven directly), the initial mechanisms of the GC differentiating effect may involve $\gamma \delta$ i-IELs which release mediators or growth factors that in turn influence $\mathrm{GC}$ differentiation during T. spiralis gut infection. As it is known, GC hyperplasia may be an important non-specific factor in host protection following an intestinal helminth infection. Indeed, our results clearly show that the DEX abolishes the jejunal GC hyperplasia in T. spiralis-infected mice (Fig. 2) and, subsequently, augments adult worm burden on day 4 p.i., when compared with infected untreated mice (Fig 1). These findings, together with those that DEX induces i-IELs death via apoptosis decreasing the total i-IEL numbers by day 4 after in vivo treatment of C57BL mice (Murosaki et al. 1997), demonstrate a 
critical role for the TCR $\gamma \delta^{+}$i-IELs in the generation of mucosal GC hyperplasia and host protective immunity following $T$. spiralis gut infection.

Another finding of this study is that the adult worm rejection starts, concurrently with a significant increase in intestinal intraepithelial $\mathrm{CD}^{+}$and $\mathrm{TCR} \alpha \beta^{+}$cells, namely by day 7 after $T$. spiralis infection of mice (Figs. 1,3). Whether or not these cells may specifically recognise $T$. spiralis-derived antigens and secrete cytokines or act as cytotoxic cells mediating lysis of the target (infected) epithelial cells by a granule-dependent mechanism is not known. However, it is well known that $\alpha \beta \mathrm{T}$ cells in i-IEL do not undergo a process of negative selection of potentially auto-reactive cells (Rocha et al. 1991, Poussier et al. 1992). Hence, these cells may be activated by superantigens or heat shock proteins (HSPs) presented in the context of MHC I-like molecules expressed by infected intestinal epithelial cells (Imani and Soloski 1991). Importantly, HSPs were found in both crude worms extract (CWE) and excretory/secretory (ES) products of the T. spiralis L1 larvae (Ko and Fan 1996) and it has been suggested that in $T$. spiralis gut infection immune response may be directed toward heat shock protein or a superantigen expressed during the development of the adult worm (Kelly et al. 1991).

The finding in this study that the increase in $\mathrm{CD} 8^{+}$ and $\alpha \beta$ i-IELs accompanied the decrease of $\mathrm{CD}^{+}$ intraepithelial lymphocytes deserves discussion. Namely, a continual decrease of $\mathrm{CD}^{+}$i-IELs during $T$. spiralis infection may be induced by Trichinella itself, since it is noteworthy that $T$. spiralis can induce immunosuppression in vivo and in vitro (Gerenčer et al. 1992). The reduction and dysfunction of $\mathrm{CD}^{+} \mathrm{T}$ cells may be a part of parasite immune evasion strategies and may result in an exacerbation of disease that induces the expression of self-HSPs by infected cells and thus promote the expansion of $\mathrm{CD}^{+}$and $\mathrm{TCR} \alpha \beta^{+}$i-IELs indirectly. But, it is also possible that the $\mathrm{CD}^{+}$and TCR $\alpha \beta^{+}$i-IELs may increase in order to compensate for the decreased $\mathrm{CD} 4^{+} \mathrm{T}$ cells. To prove this hypothesis, a more detailed analysis of intraepithelial $\mathrm{T}$ cell dysfunction underlying the pathogenesis of trichinellosis should be performed.

Why and where the i-IELs population disappears coincidentally with maximal enteropathy is still not clear. The possible explanations are exactly as it has been proposed previously (Garside et al. 1992); it may simply reflect the severe damage to the epithelium or a decline in numbers after rejection of adult worms and therefore the loss of antigenic stimulus.

Acknowledgement. We thank Nataša Briški, B.A. for reading this manuscript and providing linguistic assistance.

\section{REFERENCES}

BOISMENU R., HAVRAN W.L. 1994: Modulation of epithelial cell growth by intraepithelial $\gamma \delta \mathrm{T}$ cells. Science 266: 1253-1255.

BOISMENU R., FENG L., XIA Y.Y., CHANG J.C.C., HAVRAN W.L. 1996: Chemokine expression by intraepithelial $\gamma \delta \mathrm{T}$ cells. Implications for recruitment of inflammatory cells to damaged epithelia. J. Immunol. 157: 985-992.

BOŽIĆ F., FORČIĆ D., MAŽURAN R., MARINCULIĆ A., KOZARIĆ Z., STOJČEVIĆ D. 1998: $\gamma \delta$ TCR $^{+}$intestinal intraepithelial lymphocytes (i-IEL) in reaction against intestinal nematode Trichinella spiralis. Comp. Immunol. Microbiol. Infect. Dis. 21: 201-214.

DILLON S.B., DALTON B.J., MacDONALD T.T. 1986: Lymphokine production by mitogen and antigen activated mouse intraepithelial lymphocytes. Cell. Immunol. 103: 326-338.

GARSIDE P., GRENCIS R.K., MOWAT A.McI. 1992: T lymphocyte dependent enteropathy in murine Trichinella spiralis infection. Parasite Immunol. 14: 217-225.

GERENČER M., MARINCULIĆ A., RAPIĆ D., FRANKOVIĆ M., VALPOTIĆ I. 1992: Immunosuppression of in vivo and in vitro lymphocyte responses in swine induced by Trichinella spiralis or excretorysecretory antigens of the parasite. Vet. Parasitol. 44: 263273.

HOUSLEY R.M., MORRIS C.F., BOYLE W., RING B., BILTZ R., TERPLEY J.E., AUKERMAN S.L., DEVINE
P.L., WHITEHEAD R.H., PIERCE G.F. 1994: Keratinocyte growth factor induces proliferation of hepatocytes and epithelial cells throughout rat gastrointestinal tract. J. Clin. Invest. 94: 1764-1777.

IMANI F., SOLOSKI M.J. 1991: Heat shock proteins can regulate expression of the Tla region-encoded class $\mathrm{Ib}$ molecule Qa-1. Proc. Natl. Acad. Sci. USA 88: 1047510479.

KARMANSKA K., HOUSZKA M., MISTA D., STEFANIAK E. 1995: $\mathrm{CD}^{+}$and $\mathrm{CD}^{+}$cells during infection with Trichinella spiralis in mice. Acta Parasitol. Pol. 40: 53-57.

KELLY E.A.B., CRUZ E.S., HAUDA K.M., WASSOM D.L. 1991: IFN- $\gamma$ and IL-5 producing cells compartmentalize to different lymphoid organs in Trichinella spiralis-infected mice. J. Immunol. 147: 306-311.

KO R.C., FAN L. 1996: Heat shock response of Trichinella spiralis and T. pseudospiralis. Parasitology 112: 89-95.

LEFRANCOIS L. 1991: Phenotypic complexity of intraepithelial lymphocytes of the small intestine. J. Immunol. 147: 1746-1751.

MANSON-SMITH D.F., BRUCE R.G., PARROTT D.M.V. 1979: Villous atrophy and expulsion of intestinal Trichinella spiralis are mediated by T-cells. Cell. Immunol. 47: 285-292.

MUROSAKI S., INAGAKI-OHARA K., KUSAKA H., IKEDA H., YOSHIKAI Y. 1997: Apoptosis of intestinal intraepithelial lymphocytes induced by exogenous and 
endogenous glucocorticoids. Microbiol. Immunol. 41: 139-148.

POUSSIER P., EDOUARD P., LEE C., BINNIE M., JULIUS M. 1992: Thymus-independent development and negative selection of $\mathrm{T}$ cells expressing $\mathrm{T}$ cell receptor $\alpha / \beta$ in the intestinal epithelium: evidence for distinct circulation patterns of gut- and thymus-derived $\mathrm{T}$ lymphocytes. J. Exp. Med. 176: 187-199.

ROCHA B., VASSALLI P., GUY-GRAND D. 1991: The V $\beta$ repertoire of mouse gut homodimeric $\alpha \mathrm{CD}^{+}$intraepi- thelial $\mathrm{T}$ cell receptor $\alpha / \beta^{+}$lymphocytes reveals a major extrathymic pathway of T cell differentiation. J. Exp. Med. 173: 483-486.

WAKELIN D. 1993: Allergic inflammation as a hypothesis for the expulsion of worms from tissues. Parasitol. Today 9: $115-116$.

WAKELIN D., WILSON M.M. 1977: Transfer of immunity to Trichinella spiralis in the mouse with mesenteric lymph node cells in donors and expression of immunity in recipients. Parasitology 74: 215-224. 